\title{
Impact of AIP and inhibitory G protein alpha 2 proteins on clinical features of sporadic GH-secreting pituitary adenomas
}

\author{
Elina Ritvonen', Esa Pitkänen², Atte Karppinen³, Satu Vehkavaara', Hande Demir², \\ Anders Paetau4 ${ }^{4}$ Camilla Schalin-Jäntti ${ }^{1}$ and Auli Karhu ${ }^{2}$ \\ ${ }^{1}$ Endocrinology, Abdominal Center, University of Helsinki and Helsinki University Hospital, \\ Helsinki, Finland, ²Department of Medical and Clinical Genetics \& Genome-Scale Biology, \\ Research Programs Unit, University of Helsinki, Helsinki, Finland, ${ }^{3}$ Department of Neurosurgery, \\ University of Helsinki and Helsinki University Hospital, Helsinki, Finland, and ${ }^{4}$ Department of Pathology, \\ HUSLAB and University of Helsinki, Helsinki, Finland
}

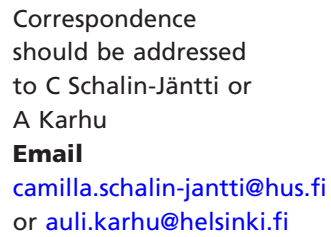

\begin{abstract}
Introduction: In sporadic acromegaly, downregulation of AIP protein of the adenomas associates with invasive tumor features and reduced responsiveness to somatostatin analogues. AIP is a regulator of $\mathrm{Ga}_{\mathrm{i}}$ signaling, but it is not known how the biological function of the $\mathrm{Ga}_{\mathrm{i}}$ pathway is controlled.

Aim: To study GNAS and AIP mutation status, AIP and $\mathrm{Ga}_{\mathrm{i}-2}$ protein expressions, $\mathrm{Ki}-67$ proliferation indices and clinical parameters in patients having primary surgery because of acromegaly at a single center between years 2000 and 2010. Results: Sixty patients (F/M, 31/29), mean age 49 (median 50), mean follow-up 7.7 years (range 0.6-14.0) underwent primary surgery. Four adenoma specimens (6.8\%) harbored an AIP and $21(35.6 \%)$ an activating GNAS (Gsp+) mutation. Altogether 13/56 (23\%) adenomas had low AIP protein levels, and 14/56 (25\%) low $\mathrm{Ga}_{\mathrm{i}-2}$ staining. In regression modeling, AIP expression associated with $\mathrm{Ga}_{\mathrm{i}-2}\left(P=2.33 \times 10^{-9}\right)$ and lower Ki-67 $(P=0.04)$. In pairwise comparison, low AIP protein predicted high GH at last follow-up (mean 7.7 years after surgery, $q=0.045$ ). Extent of treatments given for acromegaly associated with higher preoperative GH $\left(P=7.94 \times 10^{-4}\right)$, KNOSP $(P=0.003)$ and preoperative hypopituitarism $(P=0.03)$ and remission at last follow-up with change in 3-month postoperative IGF1 $\left(P=2.07 \times 10^{-7}\right)$.

Conclusions: We demonstrate, for the first time, that AIP protein expression associates with $\mathrm{Ga}_{\mathrm{i}-2}$ protein intensities in sporadic somatotropinomas, suggesting a joint regulation on somatostatin signaling. Low AIP level associates with higher proliferative activity and predicts high GH concentrations after long-term follow-up. The AIP mutation rate of $6.8 \%$ is fairly high, reflecting the genetic composition of the Finnish population.
\end{abstract}

\section{Introduction}

Pituitary adenomas occur with an overall rate of one case in 1064 of the general population (1). Regardless of their benign nature, pituitary adenomas can cause severe health problems related to mass compression, hypopituitarism as well as hormonal hypersecretion.

The majority of pituitary adenomas arise in a sporadic setting and often the exact mechanisms of tumorigenesis
() 2017 European Society of Endocrinology Printed in Great Britain remain unknown. Recent next-generation sequencing studies have shown that the somatic landscape of pituitary tumors is relatively silent $(2,3)$. The primary somatic pathogenic alteration occurring in somatotropinomas is the stimulatory guanine nucleotide (GTP)-binding protein alpha (GNAS) mutation. The GNAS gene (Gsp oncogene) is mutated in approximately $35 \%$ of sporadic 
somatotropinomas leading to constitutive activation of cyclic adenosine monophosphate (cAMP) synthesis (4).

Approximately 5\% of pituitary tumors occur in the context of hereditary tumor predisposition $(5,6)$. Germline mutations in the aryl hydrocarbon receptorinteracting protein $(A I P)$ gene predispose to pituitary adenomas (7). AIP mutations are especially enriched in patients with positive family history of homogeneous somatotropinomas and/or a young age at onset, although a subset of patients display neither of these features (5).

Recently, it was discovered that AIP deficiency is associated with pituitary tumorigenesis through elevated intracellular cAMP levels $(8,9)$. In AIP-deficient cells, constitutive activation of cAMP production was caused by defective inhibitory $\mathrm{Ga}$ protein $\left(\mathrm{Ga}_{\mathrm{i}}\right)$ signaling and $\mathrm{Ga}_{\mathrm{i}-2}$ protein levels were markedly reduced in AIP-associated somatotropinomas (9). The $\mathrm{Ga}_{\mathrm{i}}$ signaling pathway participates in the regulation of somatostatin by inhibiting growth hormone $(\mathrm{GH})$ and prolactin (PRL) secretion and cAMP synthesis through somatostatin receptors (SSTR1-5) $(10,11)$. The results indicate that AIP acts as a regulator of $\mathrm{Ga}_{\mathrm{i}}$ signaling, but it is not known how AIP controls the proper biological function of the $\mathrm{Ga}_{\mathrm{i}}$ pathway.

Recent studies have indicated that downregulation of AIP protein contributes to the pathogenesis of sporadic pituitary adenomas, regardless of AIP mutation status. In patients with acromegaly, downregulation of AIP appears to predict tumor invasiveness and reduced response to postoperative somatostatin analogue (SSA) treatment. Moreover, it has been shown that preoperative SSA treatment upregulates AIP protein levels, further supporting the role of AIP in SSA signaling $(12,13,14,15)$.

To gain insight into the possible contribution of AIP and $\mathrm{Ga}_{\mathrm{i}-2}$ protein expressions on therapeutic outcomes, we studied all consecutive patients with acromegaly $(n=60)$ who underwent primary surgery at the Helsinki University Hospital (HUH) between years 2000 and 2010. We performed AIP and $\mathrm{Ga}_{\mathrm{i}-2}$ immunohistochemical (IHC) semiquantitative analyses from the adenoma specimens, and related protein intensities to clinical data and treatment outcomes. We assessed the prevalence of AIP mutations and evaluated the possible influence of somatic GNAS mutation status on these variables.

\section{Subjects and methods}

\section{Patient material}

The patient cohort comprised 60 patients with acromegaly, who were operated on between years 2000 and 2010 at HUH $(16,17)$. Of the patients, 29 were males and 31 females with a mean age at surgery of 49 years (median 50). We retrospectively studied the corresponding 60 formalin-fixed paraffin-embedded (FFPE) pituitary adenoma samples (56 GH and $4 \mathrm{GH} / \mathrm{PRL}$ ) from these patients. Clinical data were collected before and at 3, 6 and 12 months after surgery until the last follow-up. Mean follow-up time after surgery was 7.7 years (range 0.6-14.0). Most of the patients were primarily operated on; five patients received preoperative SSA treatment. All patients underwent pituitary magnetic resonance imaging (MRI) before surgery and at 3 months after surgery, after which follow-up imaging was scheduled on an individual basis.

\section{Biochemical analysis}

$\mathrm{GH}$, prolactin (PRL) and insulin-like growth factor 1 (IGF1) measurements were obtained for each patient. Laboratory measurements were performed at HUSLAB, the laboratory of HUH, using standard accredited assays. Serum GH was determined with immunometric TR-IFMA and IGF1 with immunoenzymometric ELISA. IGF1 concentrations were expressed as percentage of upper limit of normal (\%ULN). Serum prolactin was determined with immunometric TR-IFMA.

\section{Hormonal remission and hypopituitarism}

Biochemical control was defined according to the recent consensus recommendation of 2014 as basal serum GH concentrations $<1.0 \mu \mathrm{g} / \mathrm{L}$ and normal age- and genderstandardized serum IGF1 concentrations, and for patients not on SSA treatment as suppression of serum $\mathrm{GH}$ concentration $<0.4 \mu \mathrm{g} / \mathrm{L}$ on a two-hour oral glucose tolerance test (OGTT) (18). Hypopituitarism was assessed as previously described (17).

Data on the extent of given treatments were collected as an estimate of the aggressiveness of the disease. Different treatment combinations were grouped as follows: (1) patients treated with primary surgery only, (2) patients primarily operated on, treated with adjuvant medical therapy or fractionated stereotactic radiotherapy as well as adjuvant medical treatment or patients who were operated on twice. Group 2 included the tumors most resistant to treatment.

In addition, the treatment response and remission status were assessed by dividing IGF1 response into three groups as done previously (14): group 1, controlled 
(IGF1 normalization for age and gender), group 2, partially controlled (non-normalized IGF1 with $\geq 30 \%$ reduction compared to pretreatment values) and group 3 , uncontrolled $(\leq 30 \%$ decrease in IGF1 concentration or increase compared to pretreatment values).

\section{Ethics}

The study was approved by the review board of the Helsinki University Hospital.

\section{DNA isolation and genetic screenings}

DNA from FFPE tumors was isolated with NucleoSpin FFPE DNA isolation kit (Macherey-Nagel, Düren, Germany). Mutation screening of AIP was performed using PCR primers designed for FFPE-isolated DNA (Supplementary Table 1, see section on supplementary data given at the end of this article). All six exons and exon-intron junctions were screened. Gain-of-function mutations of the GNAS gene at codons 201 and 227 (Gsp oncogene) were screened as previously described (19). The DNA fragments were amplified using AmpliTaqGold enzyme (Applied Biosystems) and purified using ExoSAP-IT PCR Purification Kit (USB Corporation, Cleveland, OH, USA). The sequencing reactions were performed utilizing the Big Dye Terminator v.3.1 Kit and ABI3730 Automatic DNA Sequencer (Applied Biosystems).

\section{Immunohistochemistry}

Antibodies used were mouse monoclonal antibody against AIP (clone35-2, Novus Biologicals LLC, Littleton, CO, USA; 1:500), $\mathrm{Ga}_{\mathrm{i}-2}$ (T19, sc-7276, Santa Cruz, 1:70) and Ki-67 (MIB-1, M7240, Dako; 1:200). Anti-mouse/rabbit/rat secondary antibody, Poly-HRP-GAM/R/R (DPVB55HRP, Immunologic, Duiven, Netherlands) and DAB chromogen (Thermo Fisher Scientific) were used for detection. AIP protein expressions were semiquantitatively scored according to intensity ( 0 , negative; 1 , weak; 2 , moderate; 3 , strong) and expression pattern (1, patchy; 2 , diffuse) as previously described $(14,20,21)$. The final protein scores were calculated by multiplying intensity $\times$ expression pattern. $\mathrm{Ga}_{\mathrm{i}-2}$ immunoreaction was scored in a similar way to AIP. Ki-67 scores were obtained by calculating the average percentage of stained nucleus among the cell population. Images were acquired with Leica DM LB microscope (Meyer Instruments, Houston, TX, USA), Olympus DP50 camera (Olympus Corporation) and Studio Lite software (Licor, Lincoln, NE, USA).

\section{Statistical analyses}

Statistical analysis was performed using R (version 3.0.2) and Python (version 2.7, packages NumPy, SciPy and StatsModels).

AIP and $\mathrm{Ga}_{\mathrm{i}-2}$ levels were categorized into two groups according to the semiquantitative scoring (0-3: low; 4-6: high). Association of both AIP and $\mathrm{Ga}_{\mathrm{i}-2}$ to a number of clinical variables was tested using the Mann-Whitney $U$ test (SciPy function mannwhitneyu) similar to (14). Both nominal $P$ values and the false discovery rate (FDR) adjusted $P$ values ( $q$-values) corrected with the BenjaminiHochberg method were calculated.

In addition to pairwise tests, we performed linear regression modeling to account for the dependencies between clinical and genetic variables. A separate linear regression model was constructed to model AIP and $\mathrm{Ga}_{\mathrm{i}-2}$ protein levels, as well as the extent of treatments, remission status and the change in pre- and post-treatment IGF1 concentrations $(\triangle \mathrm{IGF} 1, \% \mathrm{ULN})$. An iterative procedure was used to find a linear model best predicting each of these variables, given clinical and genetic data. The set of explanatory variables considered for each model is described in Supplementary Table 2.

In each of the iterations, the explanatory variable that yielded the highest increase in the $R^{2}$ adjusted for the number of model variables was added to the model. This procedure was initiated with a model containing no variables. To avoid overfitting while explaining as much variance in data as possible, the model with the lowest Bayesian information criterion (BIC) value was selected as the final model.

\section{Results}

\section{AIP and GNAS mutations and clinical characteristics of the patient cohort}

All 60 FFPE tumors were successfully sequenced and analyzed for AIP and GNAS mutations. An AIP mutation was identified in four tumors $(4 / 59,6.8 \%)$. A Finnish founder mutation, c.40C $>\mathrm{T}$ (Q14X), was found in three tumors and, in one tumor, a short out-of-frame deletion c.70>89delGAGCTCCCGGACTTTCAAGA (ENST00000279146) was observed. These mutations unambiguously resulting in a truncating transcript showed loss of the wild-type allele (LOH) as well (Fig. 1A). AIPmut+ patients were 18,29, 35 and 42 years at diagnosis (Table 1). Gain-of-function GNAS mutations (Gsp+) were observed in 21/59 (35.6\%) of tumors. Exon 8 mutation, c.1025C > T (R201C), was present in 17 tumors, and 


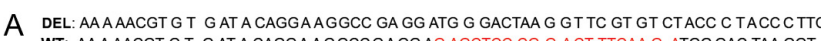
WT: AAAAACGT GT GAT A CAGGAAGGCCGAGG AG AGCTCC CG G ACT TTCAA $G$ ATGG GAC TAA GGT
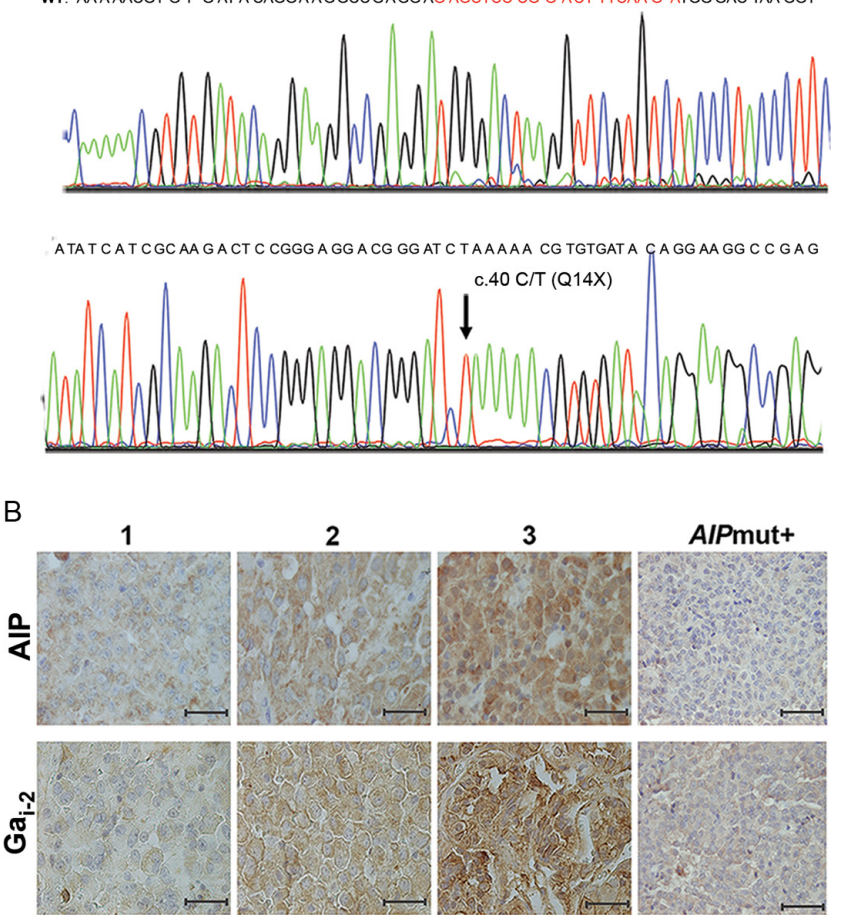

Figure 1

(A) AIP exon 1 mutations found in sequenced somatotropinomas; a short out-of-the-frame c.70 > 89delGAGCTCCCGGACTTTCAAGA deletion (upper panel) and a Finnish Q14X nonsense mutation (lower panel) with LOH. The upper panel shows the wild-type (WT) and the mutant allele sequences. The deleted region is colored red in the WT sequence. The exact deletion breaking points were confirmed by sequencing the amplicon in both directions.

(B) Immunostainings for AIP and $\mathrm{Ga}_{\mathrm{i}-2}$ proteins in somatotropinomas. The upper panel shows diffuse cytoplasmic AIP immunoreactions and the lower panel cytoplasmic/membranous $\mathrm{Ga}_{\mathrm{i}-2}$ stainings in corresponding pituitary tumors. $1=$ weak, $2=$ moderate and $3=$ strong immunoreaction intensity. AIPmut+= AIP mutation-positive somatotropinoma. Scale bar $=10 \mu \mathrm{m}$.

c.1025C > A (R201S) and c.1026G > A (R201H) mutations were both identified once. Exon 9 mutations, c.1104A>G (Q227R) and c.1104A > T (Q227L), were detected in one tumor each (ENST00000371085). AIP and GNAS mutations were mutually exclusive.

Characteristics of the 60 patients, grouped according to GNAS mutation positivity ( $G s p+, n=21)$, wild-type $(n=35)$ or $A I P$ mutation positivity (AIPmut+, $n=4)$ are given in Table 1. AIPmut+ patients tended to be younger at diagnosis (31 years vs 52 and 49 years for Gsp+ and wild-type tumors, respectively), were all characterized by macroadenomas and, in $75 \%$ of cases, by a KNOSP grade $\geq 2$ (Table 1$)$. At three months after surgery, 67\% $(n=40 / 58)$ was in hormonal remission and at last follow-up, after a mean 7.7 (range 0.6-14.0) years 75\% $(n=45 / 58)$.

Fifty-four patients were operated on once and 6 patients underwent reoperation. Six patients received radiotherapy, and 20 patients received adjuvant medical therapy (SSA in 18 cases, cabergoline in 10 cases and pegvisomant in 3 cases) (Table 1 ).

\section{Immunohistochemistry}

AIP protein immunoreactivity was observed in 55 of 56 AIPmut- tumors (98\%). Diffuse cytoplasmic staining was most prominent (Fig. 1B). Occasional nuclear immunoreactivity was also detected. Low AIP expression was observed in 12/56 (21\%) of the tumors, one of which stained negative for AIP. $\mathrm{Ga}_{\mathrm{i}-2}$ immunoreaction was positive in all adenomas, with prominent cytoplasmic and membranous staining. Low $\mathrm{Ga}_{\mathrm{i}-2}$ protein expression (intensity $\leq 3$ ) was found in 15/56 (27\%) adenomas. Tumors with low AIP and $\mathrm{Ga}_{\mathrm{i}-2}$ expression were largely overlapping. Ten tumors with low AIP level (intensity $\leq 3$ ) also showed reduced $\mathrm{Ga}_{\mathrm{i}-2}$ expression (Supplementary Fig. 1). Three AIPmut+ tumors had enough tumor material for immunostainings (two Q14X and one tumor with c.70> 89delGAGCTCCCGGACTTTCAAGA deletion). Two tumors showed negative AIP immunostaining and one tumor with Q14X mutation showed occasional cytoplasmic staining of single cells (Fig. 1B). $\mathrm{Ga}_{\mathrm{i}-2}$ protein was expressed in all three AIPmut+ somatotropinomas with reduced levels (intensity $\leq 2$ ).

\section{Relationship between AIP and $\mathrm{Ga}_{\mathrm{i}-2}$ protein expression and clinical and hormonal variables}

A strong positive association between AIP and $\mathrm{Ga}_{\mathrm{i}-2}$ protein expression levels was observed (MannWhitney $U$ test, $q=9.02 \times 10^{-5}$ ) (Table 2). AIP expression correlated inversely with last known GH $(q=0.045)$. These correlations were the only significant pairwise associations to AIP levels with false discovery rate (FDR) $<10 \%$ (Table 2 and Supplementary Tables 3 and 4). To analyze the relationship of other clinical parameters to AIP levels while controlling for $\mathrm{Ga}_{\mathrm{i}-2}$ levels, linear regression was employed. A regression model consisting of $\mathrm{Ga}_{\mathrm{i}-2}$ expression level, Ki-67 and three-month postoperative $\mathrm{GH}$ concentration was constructed, explaining 55\% of the variance in AIP levels $\left(R^{2}=0.546, P=6.03 \times 10^{-9}\right)$. 
Table 1 Clinical characteristics in 60 patients with acromegaly according to tumor type.

\begin{tabular}{l}
\hline \\
\hline Demographics \\
Gender, M/F \\
Mean age at diagnosis (years) (s.D.) \\
Mean follow-up time (years) (s.D.)* \\
Tumor characteristics \\
Tumor size, micro (\%)/macro (\%) \\
Suprasellar extension, $n(\%)$ \\
KNOSP grade 2 or above, $n(\%)$ \\
Ki-67 $<3 \%, n(\%)$ \\
Biochemical measurements at diagnosis \\
Mean GH at diagnosis ( $\mu$ g/L) (s.D.) \\
Mean IGF1 at diagnosis, $\times$ ULN (s.D.) \\
Mean PRL at diagnosis (U/L) (s.D.) \\
Hypopituitarism at diagnosis, $n(\%)$ \\
Treatment \\
Reoperation, $n(\%)$ \\
Radiotherapy, $n(\%)$ \\
Any adjunctive medical therapy, $n(\%)$ \\
Somatostatin analogue, $n(\%)$ \\
Cabergoline, $n(\%)$ \\
Pegvisomant, $n(\%)$ \\
Preoperative medical treatment \\
SSA, $n(\%)$ \\
Cabergoline, $n(\%)$
\end{tabular}

\begin{tabular}{c}
\hline ssp $^{+}(n=21)$ \\
$8 / 13$ \\
$52(15)$ \\
$7(3)$ \\
$10 / 90$ \\
$6(29)$ \\
$5(24)$ \\
$15(75), 1 \mathrm{ND}$ \\
$56(62), 14$ missing \\
$2.5(1.3)$ \\
$2900(9500)$ \\
$9(43)$ \\
$1(5)$ \\
$1(5)$ \\
$4(20), 1 \mathrm{ND}$ \\
$4(20), 1 \mathrm{ND}$ \\
$2(10), 1 \mathrm{ND}$ \\
$1(5), 1 \mathrm{ND}$ \\
$1(4.8)$ \\
$3(14.3)$
\end{tabular}

\begin{tabular}{c}
\hline Wildtype $(n=35)$ \\
$18 / 17$ \\
$49(11)$ \\
$8(3), 2 \mathrm{ND}$ \\
$14 / 86$ \\
$21(62), 1 \mathrm{ND}$ \\
$18(55), 2 \mathrm{ND}$ \\
$29(85), 1 \mathrm{ND}$ \\
$75(85)$ \\
$2.1(1.1), 3 \mathrm{ND}$ \\
$320(290)$ \\
$15(43)$ \\
$4(11)$ \\
$4(11)$ \\
$13(40), 3 \mathrm{ND}$ \\
$12(38), 3 \mathrm{ND}$ \\
$5(16), 3 \mathrm{ND}$ \\
$2(6), 3 \mathrm{ND}$ \\
$4(11.4)$ \\
$0(0)$
\end{tabular}

AIPmut $^{+}(n=4)$

$3 / 1$

$31(10)$

11 (4)

$0 / 100$

$3(75)$

$3(75)$

3 (100), 1 ND

$44(36)$

$1.9(0.9)$ $12000(24000)$

2 (50)

$1(25)$

1 (25)

3 (75)

1 (25)

3 (75)

$0(0)$

$0(0)$

$0(0)$

*Time between diagnostic MRI and last clinical follow-up visit.

ND, samples with missing data percentages may not sum up to 100 because of rounding.

As expected from the strong pairwise association, most of the variance $(43 \%)$ was explained by $\mathrm{Ga}_{\mathrm{i}-2}$ level only $\left(\mathrm{Ga}_{\mathrm{i}-2}\right.$ regression coefficient $b=0.678$, 95\% CIs $(0.492$, 0.867), $P=2.33 \times 10^{-9}$ ) (Table 3 ). In addition, the model was able to identify a weak correlation between higher AIP level and lower Ki-67 proliferation index $(b=-0.064$, 95\% CIs $(-0.126,-0.003), P=0.04)$. Also, three-month $\mathrm{GH}$ concentration improved the strength of the model, although the inverse correlation was not statistically significant (Table 3). An analogous regression model was obtained for $\mathrm{Ga}_{\mathrm{i}-2}$, consisting of the AIP level, Ki-67 scores and three-month postoperative $\mathrm{GH}$ concentration $\left(R^{2}=0.509, P=3.72 \times 10^{-8}\right.$; Table 4$)$.

The omission of five preoperatively SSA-treated patients from the data did not significantly alter statistical associations or correlations (data not shown).

\section{Predictors of the extent of given treatments and remission status at the end of follow-up}

Characteristics of patients treated with surgery only $(n=37)$ compared to patients receiving any additional treatment $(n=20)$ are given in Table 5. Patients who needed combined treatments were characterized by higher preoperative $\mathrm{GH}$ concentration $\left(q=5.63 \times 10^{-4}\right)$, higher KNOSP grade $(q=0.045)$ and higher GH $\left(q=3.01 \times 10^{-5}\right)$ and IGF1 $\left(q=1.24 \times 10^{-4}\right)$ concentrations 3 months after surgery (Mann-Whitney $U$ test). Hormonal remission at the end of follow-up was achieved in significantly fewer of the patients needing multimodal treatments compared to those who needed primary surgery only $(q=0.031)$ (Table 5).

Regression modeling demonstrated that the extent of treatments given for acromegaly associated with more invasive tumor characteristics $(b=0.432,95 \%$ CI $(0.161$, $0.703), P=0.003)$, higher preoperative $\mathrm{GH}(b=0.003,95 \%$ CIs (0.001, 0.004), $P=0.001)$ and higher prevalence of preoperative hypopituitarism $(b=0.275,95 \%$ CIs (0.023, 0.527), $P=0.033$ ) (Supplementary Table 5). Inclusion of the preoperative IGF1 and the weight of the patient contributed to the model strength, although their model coefficients were not significant. This regression model explained $47 \%$ of the variance in the extent of treatments.

Low hormonal remission status at the last follow-up associated with poor IGF1 response three months after surgery, controlled for extent of treatments and sex (three-month $\Delta \mathrm{IGF} 1$ change from $\Delta \mathrm{IGF} 1=0$ to $\Delta \mathrm{IGF} 1=2$, 
Table 2 Clinical characteristics of patients with sporadic somatotroph adenomas according to AIP expression status. AIP mutation-positive tumors are excluded from analysis.

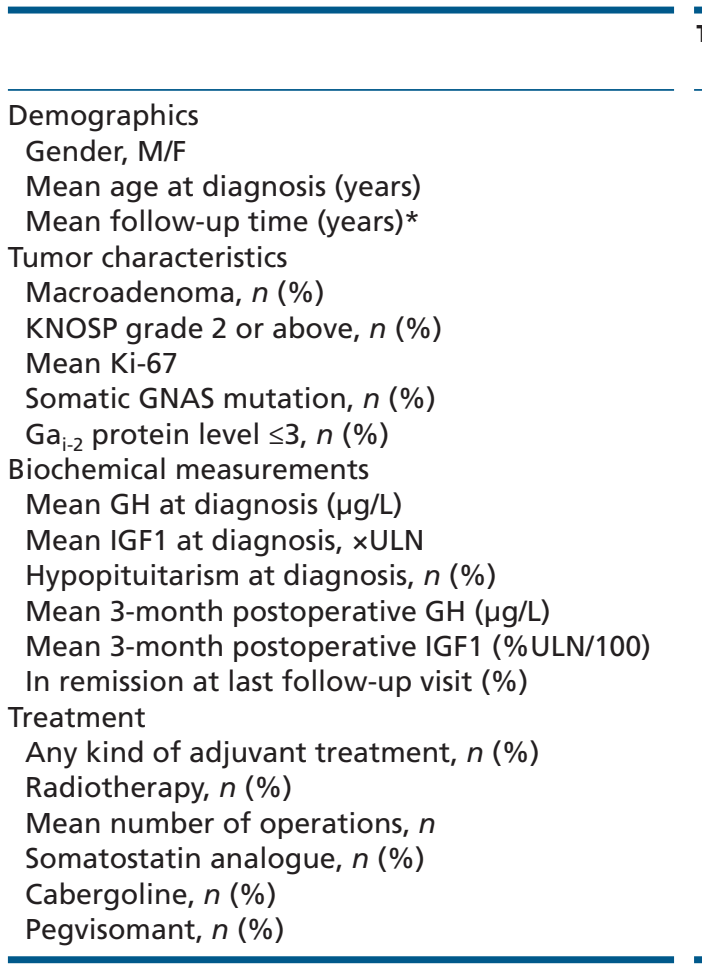

\begin{tabular}{c}
$\begin{array}{c}\text { Total } \\
(n)\end{array}$ \\
\hline \\
56 \\
56 \\
54 \\
\\
56 \\
54 \\
54 \\
56 \\
56 \\
56 \\
53 \\
56 \\
54 \\
52 \\
56 \\
53 \\
56 \\
56 \\
52 \\
52 \\
52 \\
\hline
\end{tabular}

\begin{tabular}{c} 
Low AIP \\
expression (0-3) \\
\hline
\end{tabular}

High AIP
expression $(>3)$

$07 / 05 / 16$

48.5

7.8

$12(100)$

3 (25.0)

2.1

5 (41.7)

$10(83.3)$

$56 \quad 68.5$

2.2

5 (41.7)

15

0.95

75

$5(41.7)$

$0(0)$

1.2

$4(33.3)$

$3(25.0)$

$0(0)$

expre

$19 / 25$
50.6
7.4

$37(84.1)$
$9(20.5)$
1.4
$16(36.4)$
$5(11.4)$
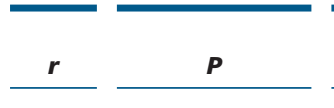

q

0.049
0.11

0.76

0.44

0.048

0.74

0.89

0.96

0.2
0.035
0.2

0.2

0.045

0.66

\subsection{3}

1

0.14

$\begin{array}{cc}1 & 1 \\ 4.51 \times 10^{-6 * * *} & 9.02 \times 10^{-5 * * *}\end{array}$

Comparison by Mann-Whitney $U$ test. Statistically significant values are displayed in bold.

$* * * P<0.001$. ${ }^{*}$ Time between diagnostic MRI and last clinical follow-up visit.

$r$, effect size; $P, P$ value; $q$, FDR-corrected $P$ value.

\begin{tabular}{clll}
67.9 & 0.044 & 0.75 & 0.97 \\
2.3 & 0.042 & 0.77 & 0.97 \\
$19(43.2)$ & 0.012 & 1 & 1 \\
7.6 & 0.24 & 0.076 & 0.4 \\
0.79 & 0.14 & 0.31 & 0.86 \\
88.1 & 0.15 & 0.36 & 0.87 \\
& & & \\
$12(27.3)$ & 0.11 & 0.49 & 0.88 \\
$5(11.4)$ & 0.16 & 0.35 & 0.87 \\
1.1 & 0.14 & 0.57 & 0.91 \\
$12(27.3)$ & 0.03 & 1 & 1 \\
$4(9.1)$ & 0.18 & 0.33 & 0.86 \\
$3(6.8)$ & 0.13 & 0.58 & 0.91 \\
\hline
\end{tabular}

$b=-0.776, \quad 95 \% \quad$ CI $\left.(-1.032,-0.520), \quad P=2.07 \times 10^{-7}\right)$

(Supplementary Table 6). A total of $65 \%$ of variance in the remission status was explained by the model.

A better IGF1 response at the last follow-up associated with less extensive treatments $(b=0.418,95 \%$ CI $(0.132$, $0.705), \quad P=0.005)$, lower preoperative prolactin level $\left(b=1.19 \times 10^{-5}, 95 \%\right.$ CI $\left.\left(5.36 \times 10^{-7}, 3.78 \times 10^{-5}\right), P=0.044\right)$ and slightly smaller preoperative $\mathrm{GH}$ concentration $(b=-0.003, \quad 95 \% \quad$ CI $\quad(-0.005, \quad-0.001), \quad P=0.014)$ (Supplementary Table 7). This model explained only $21 \%$ of the total variance in IGF1 response.

\section{Gsp mutation status and clinical characteristics}

Gain-of-function GNAS mutation (Gsp+) was observed in $21 / 59$ (35.6\%) of the tumors. Association of Gsp mutation status to a number of clinical variables was tested using the Mann-Whitney $U$ test. Gsp status had no effect on AIP or $\mathrm{Ga}_{\mathrm{i}-2}$ protein levels (AIP $P=1.0 ; \mathrm{Ga}_{\mathrm{i}-2} P=1.0$; Supplementary Table 8). Gsp+ tumors showed a nominal association with non-invasive characteristics (KNOSP (grades 0-2), $P=0.02, q=0.121)$, as well as higher preoperative prolactin levels $(P=0.02, q=0.119$, median $203.0 \mathrm{ng} / \mathrm{mL}$ (Gsp-) and $528.0 \mathrm{ng} / \mathrm{mL}(G s p+))$. However, after correcting for

Table 3 Linear regression model of AIP protein expression level.

\begin{tabular}{|c|c|c|c|}
\hline Variable & b & SE & $t$ \\
\hline Constant & 0.39 & 0.10 & 3.92 \\
\hline $\mathrm{Ga}_{\mathrm{i}-2}$ & 0.68 & 0.09 & 7.33 \\
\hline $\mathrm{Ki}-67$ & -0.06 & 0.03 & -2.12 \\
\hline Three-month GH & -0.003 & 0.002 & -1.07 \\
\hline
\end{tabular}

\begin{tabular}{|c|}
\hline $\boldsymbol{P}$ \\
\hline $2.81 \times 10^{-4 \star * *}$ \\
\hline $2.33 \times 10^{-9 * * *}$ \\
\hline $0.04 *$ \\
\hline 0.29 \\
\hline
\end{tabular}

\begin{tabular}{|c|c|}
\hline Cl lower & Cl upper \\
\hline 0.19 & 0.59 \\
\hline 0.49 & 0.86 \\
\hline-0.13 & 0.00 \\
\hline-0.01 & 0.00 \\
\hline
\end{tabular}

$n=52$, degrees of freedom $d f=48$, adjusted $R^{2}=0.55, F=21.4, \mathrm{BIC}=26.1, P=6.03 \times 10^{-9 * * *}, b=$ coefficient, SE $=$ standard error, $t=t$ statistic, $P=P$-value, $\mathrm{Cl}=95 \%$ confidence intervals. The constant term $b_{0}$ of the regression model $y=b_{0}+\sum b_{\mathrm{i}} x_{\mathrm{i}}+\varepsilon$ denoted by (Constant).

$* P<0.05$ and $* * * P<0.001$. 
Table 4 Linear regression model of $\mathrm{Ga}_{\mathrm{i}-2}$ protein expression level.

\begin{tabular}{lll}
\hline Variable & \multicolumn{1}{c}{$\boldsymbol{b}$} \\
\cline { 1 - 1 } Constant & & 0.08 \\
AIP & & 0.78 \\
Three-month GH & & 0.0003 \\
Ki-67 & 0.04 \\
\hline
\end{tabular}

\begin{tabular}{ll}
\hline \multicolumn{1}{c}{ SE } \\
\hline 0.12 \\
0.11 \\
0.003 \\
0.034 \\
\hline
\end{tabular}

\begin{tabular}{c}
\hline $\boldsymbol{t}$ \\
\hline 0.68 \\
7.32 \\
0.10 \\
1.31 \\
\hline
\end{tabular}

\begin{tabular}{l}
\hline \multicolumn{1}{c}{$\boldsymbol{P}$} \\
\hline 0.50 \\
$\mathbf{2 . 3 2} \times \mathbf{1 0}^{-\mathbf{9} * * *}$ \\
0.92 \\
0.20 \\
\hline
\end{tabular}

\begin{tabular}{c}
\hline Cl lower \\
\hline-0.16 \\
0.57 \\
-0.01 \\
-0.02 \\
\hline
\end{tabular}

\begin{tabular}{c}
\hline Cl upper \\
\hline 0.33 \\
0.99 \\
0.01 \\
0.11 \\
\hline
\end{tabular}

$n=52$, degrees of freedom $d f=48$, adjusted $R^{2}=0.51, F=18.6, \mathrm{BIC}=33.3, P=3.72 \times 10^{-8 * * *}, b=$ coefficient, SE $=$ standard error, $t=t$ statistic, $P=P$-value, $\mathrm{Cl}=95 \%$ confidence intervals. The constant term $b_{0}$ of the regression model $y=b_{0}+\sum b_{\mathrm{i}} x_{\mathrm{i}}+\varepsilon$ denoted by (Constant).

$* * * P<0.001$. Statistically significant values are displayed in bold.

multiple testing, no significant associations with FDR $<10 \%$ were detected.

\section{Discussion}

We and others have previously reported that AIP germline mutations predispose to pituitary adenomas, mostly to somatotropinomas with an aggressive disease phenotype and a poor response to SSA treatment (5, $7,15,22)$. These recent data suggest that AIP is closely involved in SSA signaling and directly correlates with the therapeutic responses in the patients. In sporadic AIPmutsomatotropinomas, preoperative SSA treatment increases AIP protein expression and the AIP protein levels seem to predict the treatment responses to SSA therapy $(12,14$, $21,23)$. Recently, we demonstrated that AIP mutations predispose to pituitary tumorigenesis through defective inhibitory GTP-binding protein (Gai) signaling and that $\mathrm{Ga}_{\mathrm{i}-2}$ protein levels were selectively reduced in AIPmutated somatotropinomas (9).
Based on these findings, we wanted to examine the possible association between somatotropinoma AIP and $\mathrm{Ga}_{\mathrm{i}-2}$ protein levels in patients with sporadic acromegaly, a majority of whom (93\%) did not receive preoperative SSA treatment, and clinical, biochemical and imaging characteristics of the patients in our cohort of patients operated on at HUH during years 2000-2010 (16, 17). We found AIP and $\mathrm{Ga}_{\mathrm{i}-2}$ protein expression levels to be strongly associated. Low AIP levels were seen together with reduced $\mathrm{Ga}_{\mathrm{i}-2}$ protein expression, supporting the earlier finding where reduced $\mathrm{Ga}_{\mathrm{i}-2}$ levels were detected in AIP-associated somatotropinomas (9). As downregulation of AIP is associated with reduced responsiveness to SSA treatment, and $\mathrm{Ga}_{\mathrm{i}}$ proteins mediate somatostatin signaling via SSTRs $(10,11,12,14,21)$, the simultaneous downregulation of $\mathrm{AIP}$ and $\mathrm{Ga}_{\mathrm{i}-2}$ may reflect a joint regulation of these proteins on SSA signaling.

Albeit the majority of the AIP protein level variance was explained by $\mathrm{Ga}_{\mathrm{i}-2}$, also higher proliferative activity (Ki-67) and three-month postoperative GH concentrations

Table 5 Comparison between patients treated by primary surgery only and patients receiving multimodal treatments.

F/M
Mean age at diagnosis (years)
Mean preoperative GH ( $\mu$ g/L)
Preoperative IGF1 (\%ULN/100)
Size (micro/macro)
KNOSP grade $>2, n(\%)$
Somatic GNAS mutation, $n(\%)$
Ga ${ }_{i-2}$ protein level $\leq 3, n(\%)$
AIP protein level $\leq 3, n$ (\%)
Mean Ki-67 proliferation index
Mean 3-month postoperative GH ( $\mu g / L)$
Mean 3-month postoperative IGF1 (\%ULN/100)
In remission at last follow-up visit ( $\%)$
Mean follow-up time (years)

\begin{tabular}{|c|c|}
\hline $\begin{array}{c}\text { Total } \\
(n)\end{array}$ & $\begin{array}{c}\text { Primary } \\
\text { surgery only }\end{array}$ \\
\hline 53 & $18 / 18$ \\
\hline 53 & 51.4 \\
\hline 53 & 42.7 \\
\hline 50 & 2.1 \\
\hline 53 & $5 / 31$ \\
\hline 53 & $4(11.1)$ \\
\hline 53 & $16(44.4)$ \\
\hline 53 & $10(27.8)$ \\
\hline 53 & $7(19.4)$ \\
\hline 51 & 1.6 \\
\hline 52 & 3.4 \\
\hline 50 & 0.54 \\
\hline 52 & 97.1 \\
\hline 52 & 7.1 \\
\hline
\end{tabular}

$\begin{gathered}\text { Primary surgery + any } \\ \text { other treatment } \\ \text { modality }\end{gathered}$
$9 / 8$
47.8
129.8
2.4
$2 / 15$
$8(47.1)$
$4(23.5)$
$5(29.4)$
$5(29.4)$
1.6
22.3
1.44
64.7
8.8

\begin{tabular}{l}
\hline $\boldsymbol{r}$ \\
\hline 0.03 \\
0.11 \\
0.54 \\
0.12 \\
0.029 \\
0.40 \\
0.20 \\
0.017 \\
0.11 \\
0.029 \\
0.63 \\
0.59 \\
0.44 \\
0.28 \\
\hline
\end{tabular}

\begin{tabular}{l}
\hline \multicolumn{1}{c}{$\boldsymbol{P}$} \\
\hline 1 \\
0.43 \\
$\mathbf{3 . 7 6} \times \mathbf{1 0}^{-5 * * *}$ \\
0.40 \\
1 \\
$\mathbf{0 . 0 0 6 * *}$ \\
0.225 \\
1 \\
0.49 \\
0.84 \\
$\mathbf{7 . 5 3} \times \mathbf{1 0}-\mathbf{7 * * *}$ \\
$\mathbf{7 . 2 8} \times \mathbf{1 0}-\mathbf{6 * * *}$ \\
$\mathbf{0 . 0 0 3 * *}$ \\
$\mathbf{0 . 0 4 4 *}$ \\
\hline
\end{tabular}

\begin{tabular}{l}
\hline \multicolumn{1}{c}{$\mathbf{Q}$} \\
\hline 1 \\
0.89 \\
$\mathbf{5 . 6 3} \times \mathbf{1 0}^{-4 * * *}$ \\
0.89 \\
1 \\
$\mathbf{0 . 0 4 5}$ \\
0.83 \\
1 \\
0.89 \\
1 \\
$\mathbf{3 . 0 1} \times \mathbf{1 0}$ \\
$\mathbf{1 . 2 5} \times \mathbf{1 0}-\mathbf{4 * * *}$ \\
$\mathbf{0 . 0 3 1 *}$ \\
0.23 \\
\hline
\end{tabular}

Comparison by Mann-Whitney $U$ test. Statistically significant values are displayed in bold.

$\star P<0.05, * * P<0.01$ and $* * * P<0.001$.

$r$, effect size ( $Z /$ sqrt $(N)$, where $Z$ is the $Z$ score corresponding to the $U$ statistic and $N$ is the total number of samples); $P$, Mann-Whitney $U$ test $P$ value; $q$, FDR-corrected $P$ value. 
associated with reduced AIP protein expression. This supports earlier findings that AIPmut- somatotropinomas with reduced AIP levels share characteristics with AIPmut+ tumors. It was demonstrated that AIP downregulation is accompanied by higher proliferative activity and that AIP mutation-associated patients tend to have less effective reduction of $\mathrm{GH}$ and IGF1 levels, indicating poorer response to SSA treatments $(14,20,22)$. In addition, it has been reported that low AIP level is a good marker of invasiveness in somatotropinomas $(14,21,23)$. In the present study, however, no association between invasive features and AIP levels was detected. The reason for this difference might be the fact that in our tumor set, the total number of tumors having aggressive features was low (Table 1). However, low tumor AIP protein levels were significantly associated with higher GH concentrations at last follow-up, which occurred at a mean 7.7 years after surgery $(q=0.045)$. This is, to the best of our knowledge, the first cohort study on sporadic acromegaly evaluating the possible influence of AIP protein levels of the primary tumors on long-term hormonal outcome, demonstrating that low AIP protein levels predict high GH concentrations even when more than 7 years after primary treatment have elapsed. In addition, regression modeling indicated that the extent of given treatments was best explained by the preoperative $\mathrm{GH}$ concentration $\left(P=7.94 \times 10^{-4}\right)$, KNOSP $(P=0.003)$ and preoperative hypopituitarism $(P=0.03)$. Remission at the last follow-up was best explained by the change in 3-month postoperative IGF1 $\left(P=2.07 \times 10^{-7}\right)$. Both low AIP protein level of the primary tumor, a small reduction only in IGF1 concentration 3 months after surgery, as well as preoperative $\mathrm{GH}$, KNOSP grade and preoperative hypopituitarism thus seem to represent early and useful indicators of poor long-term hormonal remission and treatment resistance in sporadic acromegaly.

The current and previous studies suggest that downregulation of AIP protein contributes to the pathogenesis of a subset of AIPmut- somatotropinomas $(12,13,14,15,21,23)$. Currently, the mechanisms involved in the reduced AIP levels in these tumors are not known. Low somatic single-nucleotide and structural variant DNA damage rates in pituitary adenomas $(2,3)$ indicate the involvement of other mechanisms. It has been suggested that alterations in epigenetic regulation may play a prominent role in pituitary neoplasia, likely via loss or reduced expression of tumor suppressor genes (24). Also numerical chromosomal abnormality, aneuploidy and characterize these tumors (3, 25). Hence, these mechanisms may be promising candidates in explaining reduced expression of AIP in these more aggressive AIPmut- somatotropinomas.

Although it has been proposed that Gsp+ associated tumors are more often microadenomas, lacking invasive features, and that patients with Gsp+ associated tumor respond better to SSA treatment, larger studies have shown that there is no difference in clinical features and outcome of patients with or without Gsp mutation $(26,27,28)$. Consistent with this, we did not observe any correlation between adenomas with or without Gsp mutation and clinical characteristics. Further, our results agree with the study of Jaffrain-Rea et al. (14) in that no effect on AIP staining intensities was observed between Gsp genotypes. Although inhibitory $\mathrm{Ga}_{\mathrm{i}}$ signaling counteracts the stimulatory action of GNAS $\left(\mathrm{Ga}_{\mathrm{s}}\right)$ in cAMP synthesis, no correlation between $G s p+$ genotype and $\mathrm{Ga}_{\mathrm{i}-2}$ protein levels was detected.

Although AIP IHC is an important application in research use, the value of IHC for the detection of AIP germline mutation is more challenging. Many of $A I P$ alterations are characterized by an exchange of single amino acid or in-frame insertion/deletion (indels) (5). In such cases, AIP IHC may lead to positive immunostaining, regardless of $A I P$-associated background of the tumor. Therefore, standard germline sequencing methods should be used for the identification of AIP germline mutations. For instance, multiplex ligation-dependent probe amplification (MLPA) and whole-genome sequencing (WGS) are methods of choice for identification of larger AIP germline indels.

In genetically heterogeneous populations, the prevalence of AIP mutations is generally less than $4 \%$ $(20,29,30,31,32)$. In a Finnish setting, previous AIP mutation frequency studies have focused on a defined, homogenous population from Northern Finland or patients with early-onset disease $(7,29,33)$. In the original study of Vierimaa et al. (7) AIP mutations accounted for $16 \%$ of population-based acromegaly patients from Northern Finland. In the current study, we examined the prevalence of AIP mutations in a cohort of 60 consecutive patients with sporadic acromegaly, operated at the HUH during 2000-2010, representative of the population in Southern Finland. Normal DNA samples were not available from the patients to perform germline AIP analysis. However, the appearance of a Finnish founder mutation, Q14X, supports the germline origin of this mutation. The AIP mutation prevalence of $6.7 \%$ seen in this apparently sporadic somatotropinoma setting is markedly higher than those reported in several prospective international cohort studies $(5,30,31,32)$. 
This reflects the genetically homogenous structure of the Finnish population (34), where a Finnish AIP founder mutation (Q14X) accounts for the majority of the pathogenic variants $(5,7,29,33)$. In Finnish patients, we have so far identified altogether 29 Q14X mutations (21 familial and 8 apparently sporadic cases) and in addition, in patients with sporadic acromegaly, we have detected one splice-site mutation (IVS3-1G>A) (7) and two patients with short deletions: c.733 > 735delGAG (9) and c.70>89delGAGCTCCCGGACTTTCAAGA (present study). The rareness of these variants compared to the Q14X mutation indicates that they represent more recent events in the Finnish population.

In summary, we have now for the first time shown that in sporadic somatotropinomas, AIP protein expression levels associate with $\mathrm{Ga}_{\mathrm{i}-2}$ protein intensities, possibly indicating a synergetic effect of these proteins on SSA signaling. In addition, higher proliferation activity and postoperative $\mathrm{GH}$ levels were seen together with reduced AIP protein levels, indicating a more aggressive nature of the tumors and worse treatment response. Both low AIP protein level of the primary tumor as well as a small reduction only in IGF1 concentration 3 months after surgery seem to serve as early and useful predictors of treatment resistance and poor long-term hormonal remission in sporadic acromegaly. In addition, the AIP mutation rate of $6.8 \%$ in our Finnish population-based series of somatotropinomas is higher than that seen in many other international cohort studies, likely reflecting the special genetic composition of the Finnish population.

Supplementary data

This is linked to the online version of the paper at http://dx.doi.org/10.1530/ EJE-16-0620.

\section{Declaration of interest}

The authors declare that there is no conflict of interest that could be perceived as prejudicing the impartiality of the research reported.

\section{Funding}

This study was supported by the Academy of Finland (grant number 250345, 2012-2017), the Cancer Society of Finland (grant number 4704019, 2015), Finska Läkaresällskapet, Novartis Finland and Pfizer Oy.

\section{Author contribution statement}

All authors reviewed the manuscript and approved the final version for publication. E Ritvonen is a principal investigator of the present study and wrote the manuscript together with E Pitkänen, A Karhu and C SchalinJäntti. E Pitkänen performed all statistical analyses. A Karppinen and $S$ Vehkavaara participated in gathering the patient data. A Paetau was consulted about immunohistochemical analyses. H Demir participated in genetic analyses. A Karhu and C Schalin-Jäntti were responsible for conceiving the idea of the present study and supervised the study.

\section{Acknowledgements}

The authors thank Sini Nieminen, Alison Ollikainen, Helena Ranta-aho, Inga-Lill Svedberg and lina Vuoristo for technical assistance, and Nina Honkanen for collecting the paraffin samples. The Biomedicum Imaging Unit is acknowledged for the microscopy service.

\section{References}

1 Daly AF, Rixhon M, Adam C, Dempegioti A, Tichomirowa MA $\&$ Beckers A. High prevalence of pituitary adenomas: a crosssectional study in the province of Liege, Belgium. Journal of Clinical Endocrinology and Metabolism 200691 4769-4775. (doi:10.1210/ jc.2006-1668)

2 Newey PJ, Nesbit MA, Rimmer AJ, Head RA, Gorvin CM, Attar M, Gregory L, Wass JA, Buck D, Karavitaki N et al. Whole-exome sequencing studies of nonfunctioning pituitary adenomas. Journal of Clinical Endocrinology and Metabolism 201398 E796-E800. (doi:10.1210/jc.2012-4028)

3 Välimäki N, Demir H, Pitkänen E, Kaasinen E, Karppinen A, Kivipelto L, Schalin-Jäntti C, Aaltonen LA \& Karhu A. Whole-genome sequencing of growth hormone $(\mathrm{GH})$-secreting pituitary adenomas. Journal of Clinical Endocrinology and Metabolism 2015100 3918-3927. (doi:10.1210/jc.2015-3129)

4 Vallar L, Spada A \& Giannattasio G. Altered Gs and adenylate cyclase activity in human GH-secreting pituitary adenomas. Nature 1987330 566-568. (doi:10.1038/330566a0)

5 Beckers A, Aaltonen LA, Daly AF \& Karhu A. Familial isolated pituitary adenomas (FIPA) and the pituitary adenoma predisposition due to mutations in the aryl hydrocarbon receptor interacting protein (AIP) gene. Endocrine Reviews 201334 239-277. (doi:10.1210/er.2012-1013)

6 Trivellin G, Daly AF, Faucz FR, Yuan B, Rostomyan L, Larco DO, Schernthaner-Reiter MH, Szarek E, Leal LF, Caberg J-H et al. Gigantism and acromegaly due to Xq26 microduplications and GPR101 mutation. New England Journal of Medicine $20143712363-2374$. (doi:10.1056/NEJMoa1408028)

7 Vierimaa O, Georgitsi M, Lehtonen R, Vahteristo P, Kokko A, Raitila A, Tuppurainen K, Ebeling TM, Salmela PI, Paschke R et al. Pituitary adenoma predisposition caused by germline mutations in the AIP gene. Science 2006312 1228-1230. (doi:10.1126/science.1126100)

8 Formosa R, Xuereb-Anastasi A \& Vassallo J. AIP regulates cAMP signalling and growth hormone secretion in GH3 cells. Endocrine-Related Cancer 201320 495-505. (doi:10.1530/ERC-13-0043)

9 Tuominen I, Heliövaara E, Raitila A, Rautiainen M, Mehine M, Katainen R, Donner I, Aittomäki V, Lehtonen HJ, Ahlsten M et al. AIP inactivation leads to pituitary tumorigenesis through defective Gai-cAMP signaling. Oncogene 201534 1174-1184. (doi:10.1038/ onc.2014.50)

10 Birnbaumer L. Receptor-to-effector signaling through G proteins: roles for beta gamma dimers as well as alpha subunits. Cell $1992 \mathbf{7 1}$ 1069-1072. (doi:10.1016/S0092-8674(05)80056-X)

11 Zatelli MC, Piccin D, Tagliati F, Ambrosio MR, Margutti A, Padovani R, Scanarini M, Culler MD \& degli Uberti EC. Somatostatin receptor subtype 1 selective activation in human growth hormone $(\mathrm{GH})$ and prolactin (PRL) - secreting pituitary adenomas: effects on cell viability, GH, and PRL secretion. Journal of Clinical Endocrinology and Metabolism 200388 2797-2802. (doi:10.1210/jc.2002-021825)

12 Chahal HS, Trivellin G, Leontiou CA, Alband N, Fowkes RC, Tahir A, Igreja SC, Chapple JP, Jordan S, Lupp A et al. Somatostatin analogs modulate AIP in somatotroph adenomas: the role of the ZAC1 pathway. Journal Clinical Endocrinology and Metabolism 201297 E1411-E1420. (doi:10.1210/jc.2012-1111) 
13 Kasuki L, Vieira Neto L, Wildemberg LE, Colli LM, de Castro M, Takiya CM \& Gadelha MR. AIP expression in sporadic somatotropinomas is a predictor of the response to octreotide LAR therapy independent of SSTR2 expression. Endocrine-Related Cancer 201219 L25-L29. (doi:10.1530/ERC-12-0020)

14 Jaffrain-Rea ML, Rotondi S, Turchi A, Occhi G, Barlier A, Peverelli E, Rostomyan L, Defilles C, Angelini M, Oliva MA et al. Somatostatin analogues increase AIP expression in somatotropinomas, irrespective of Gsp mutations. Endocrine-Related Cancer 201320 753-766. (doi:10.1530/ERC-12-0322)

15 Iacovazzo D, Carlsen E, Lugli F, Chiloiro S, Piacentini S, Bianchi A, Giampietro A, Mormando M, Clear AJ, Doglietto F et al. Factors predicting pasireotide responsiveness in somatotroph pituitary adenomas resistant to first-generation somatostatin analogues: an immunohistochemical study. European Journal of Endocrinology 2016 174 241-250. (doi:10.1530/EJE-15-0832)

16 Karppinen A, Kivipelto L, Vehkavaara S, Ritvonen E, Tikkanen E, Kivisaari R, Hernesniemi J, Setälä K, Schalin-Jäntti C \& Niemelä M. Transition from microscopic to endoscopic transsphenoidal surgery for nonfunctional pituitary adenomas. World Neurosurgery 201584 48-57. (doi:10.1016/j.wneu.2015.02.024)

17 Ritvonen E, Karppinen A, Sintonen H, Vehkavaara S, Kivipelto L, Roine RP, Niemelä M \& Schalin-Jäntti C. Normal long-term healthrelated quality of life can be achieved in patients with functional pituitary adenomas having surgery as primary treatment. Clinical Endocrinology 201582 412-421. (doi:10.1111/cen.12550)

18 Giustina A, Chanson P, Kleinberg D, Bronstein MD, Clemmons DR, Klibanski A, van der Lely AJ, Strasburger CJ, Lamberts SW, Ho KK et al. Expert consensus document: a consensus on the medical treatment of acromegaly. Nature Review Endocrinology 201410 243-248. (doi:10.1038/nrendo.2014.21)

19 Lania A, Persani L, Ballaré E, Mantovani S, Losa M \& Spada A. Constitutively active Gsa is associated with an increased phosphodiesterase activity in human growth hormone-secreting adenomas. Journal of Clinical Endocrinology and Metabolism $1998 \mathbf{8 3}$ 1624-1628. (doi:10.1210/jc.83.5.1624)

20 Leontiou CA, Gueorguiev M, van der Spuy J, Quinton R, Lolli F, Hassan S, Chahal HS, Igreja SC, Jordan S, Rowe J et al. The role of the aryl hydrocarbon receptor-interacting protein gene in familial and sporadic pituitary adenomas. Journal of Clinical Endocrinology and Metabolism 200893 2390-2401. (doi:10.1210/jc.2007-2611)

21 Kasuki Jomori de Pinho L, Vieira Neto L, Armondi Wildemberg LE, Gasparetto EL, Marcondes J, de Almeida Nunes B, Takiya CM \& Gadelha MR. Low aryl hydrocarbon receptor-interacting protein expression is a better marker of invasiveness in somatotropinomas than Ki-67 and p53. Neuroendocrinology 201194 39-48. (doi:10.1159/000322787)

22 Daly AF, Tichomirowa MA, Petrossians P, Heliövaara E, JaffrainRea M-L, Barlier A, Naves LA, Ebeling T, Karhu A, Raappana A et al. Clinical characteristics and therapeutic responses in patients with germ-line AIP mutations and pituitary adenomas: an international collaborative study. Journal of Clinical Endocrinology and Metabolism 201095 E373-E383. (doi:10.1210/jc.2009-2556)

23 Jaffrain-Rea ML, Angelini M, Gargano D, Tichomirowa MA, Daly AF, Vanbellinghen JF, D"Innocenzo E, Barlier A, Giangaspero F,
Esposito V et al. Expression of aryl hydrocarbon receptor (AHR) and AHR-interacting protein in pituitary adenomas: pathological and clinical implications. Endocrine-Related Cancer 200916 1029-1043. (doi:10.1677/ERC-09-0094)

24 Dudley KJ, Revill K, Clayton RN \& Farrell WE. Pituitary tumours: all silent on the epigenetics front. Journal of Molecular Endocrinology 2009 42 461-468. (doi:10.1677/JME-09-0009)

25 Chesnokova V \& Melmed S. Pituitary senescence: the evolving role of Pttg. Molecular and Cellular Endocrinology 2010326 55-59. (doi:10.1016/j.mce.2010.02.012)

26 Spada A, Arosio M, Bochicchio D, Bazzoni N, Vallar L, Bassetti M \& Faglia G. Clinical biochemical and morphological correlates in patients bearing growth hormone secreting tumors with or without constitutively active adenylyl cyclase. Journal of Clinical Endocrinology and Metabolism 199071 1421-1426. (doi:10.1210/jcem-71-6-1421)

27 Adams EF, Brockmeier S, Friedmann E, Roth M, Buchfelder M \& Fahlbusch R. Clinical and biochemical characteristics of acromegalic patients harboring gsp-positive and gsp-negative pituitary tumors. Neurosurgery 199633 198-203. (doi:10.1227/00006123-19930800000003)

28 Peverelli E, Mantovani G, Lania AG \& Spada A. cAMP in the pituitary: an old messenger for multiple signals. Journal of Molecular Endocrinology 201352 R67-R77. (doi:10.1530/JME-13-0172)

29 Georgitsi M, Raitila A, Karhu A, Tuppurainen K, Makinen MJ, Vierimaa O, Paschke R, Saeger W, van der Luijt RB, Sane T et al. Molecular diagnosis of pituitary adenoma predisposition caused by aryl hydrocarbon receptor-interacting protein gene mutations. PNAS 2007104 4101-4105. (doi:10.1073/pnas.0700004104)

30 Barlier A, Vanbellinghen J-F, Daly AF, Silvy M, Jaffrain-Rea M-L, Trouillas J, Tamagno G, Cazabat L, Bours V, Brue T et al. Mutations in the aryl hydrocarbon receptor interacting protein gene are not highly prevalent among subjects with sporadic pituitary adenomas. Journal of Clinical Endocrinology and Metabolism 200792 1952-1955. (doi:10.1210/jc.2006-2702)

31 Occhi G, Trivellin G, Ceccato F, De Lazzari P, Giorgi G, Demattè S, Grimaldi F, Castello R, Davì MV, Arnaldi G et al. Prevalence of AIP mutations in a large series of sporadic Italian acromegalic patients and evaluation of CDKN1B status in acromegalic patients with multiple endocrine neoplasia. European Journal of Endocrinology 2010 163 369-736. (doi:10.1530/EJE-10-0327)

32 Cazabat L, Bouligand J, Salenave S, Bernier M, Gaillard S, Parker F, Young J, Guiochon-Mantel A \& Chanson P. Germline AIP mutations in apparently sporadic pituitary adenomas: prevalence in a prospective single-center cohort of 443 patients. Journal of Clinical Endocrinology and Metabolism 201297 E663-E670. (doi:10.1210/ jc.2011-2291)

33 Georgitsi M, De Menis E, Cannavò S, Mäkinen MJ, Tuppurainen K, Pauletto P, Curtò L, Weil RJ, Paschke R, Zielinski G et al. Aryl hydrocarbon receptor interacting protein (AIP) gene mutation analysis in children and adolescents with sporadic pituitary adenomas. Clinical Endocrinology 200869 621-627. (doi:10.1111/ j.1365-2265.2008.03266.x)

34 Peltonen L, Jalanko A \& Varilo T. Molecular genetics of the Finnish disease heritage. Human Molecular Genetics 19998 1913-1923. (doi:10.1093/hmg/8.10.1913)

Received 26 July 2016

Revised version received 12 September 2016 Accepted 22 November 2016 